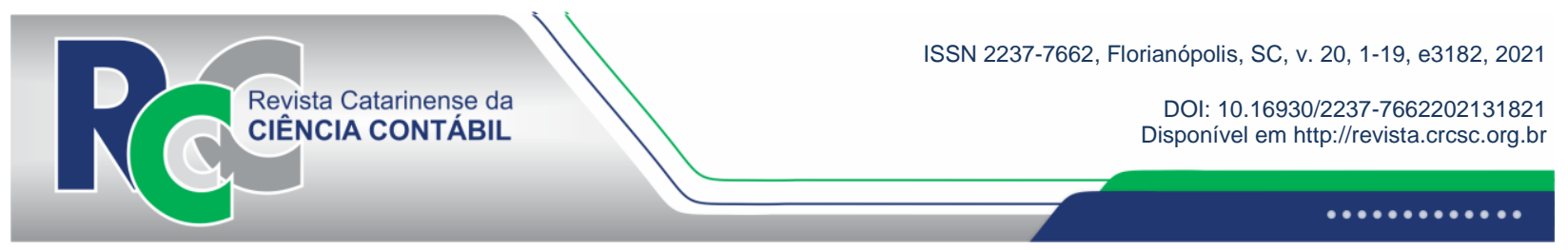

\title{
ENSINO REMOTO EMERGENCIAL NA PERCEPÇÃO DE ALUNOS PRESENCIAIS DE CIÊNCIAS CONTÁBEIS DURANTE A PANDEMIA DE COVID-19
}

\author{
EMERGENCY REMOTE EDUCATION IN THE PERCEPTION OF ON-SITE ACCOUNTING \\ SCIENCES STUDENTS DURING THE COVID-19 PANDEMIC
}

\author{
CRISTIANO SAUSEN SOARES \\ Universidade Federal de Santa Maria. Endereço: Av. Roraima, $n^{a}$ 1000, \\ Cidade Universitária, CCSH, Prédio 74C, Sala 4346 | Camobi | 97105-900 \\ | Santa Maria/RS | Brasil. \\ (D) https://orcid.org/0000-0002-6427-8699 \\ cristianocontador@hotmail.com
}

\section{DUANNE EMANUEL LEAL GUIMARÃES \\ Universidade Federal de Santa Maria. Endereço: Rua Professor Madeira, $n^{o} 1760 \mid$ Horto | 64.052-480 | Teresina/PI | Brasil. \\ (D) https://orcid.org/0000-0002-8666-3109 \\ emanuelduanneguimaraes@gmail.com}

\section{TATIÉLI VIEIRA DE SOUZA}

Universidade Federal de Santa Maria. Endereço: Rua Encantado, $n^{\circ} 87$ |

Avenida | 96815-240 | Santa Cruz do Sul/RS | Brasil.

(D) https://orcid.org/0000-0001-9947-8394

tatielivieiras@gmail.com

\section{RESUMO}

O estudo objetivou investigar a percepção de acadêmicos presenciais do curso de ciências contábeis de uma universidade pública que adotou o ensino remoto emergencial durante a pandemia de Covid19 no Brasil, ressaltando-se os aspectos que favorecem ou dificultam a aprendizagem. Foi realizado um estudo qualitativo e descritivo, com dados coletados mediante 4 grupos focais com a participação de 80 alunos de um curso presencial de graduação em ciências contábeis. Os resultados indicam que os alunos percebem como aspectos facilitadores do ensino remoto os fatores estruturais (flexibilização nos prazos para entrega de atividades), pessoais e coletivos (autonomia no processo de aprendizagem) e didático-pedagógicos (uso de metodologias ativas pelo professor). Quanto aos aspectos que dificultam a aprendizagem, destacam-se os fatores externos (falta de acesso à internet), individuais (não manter rotina de estudos e elevação do nível de estresses) e práticas docentes tradicionais (aulas

Editado em português e inglês. Versão original em português.

Recebido em 20/6/2021. Revisado em 12/8/2021. Aceito em 17/9/2021 pelos Prof. Dr. Sérgio Murilo Petri (Editor-Chefe) e Prof. Dr. Sandro Vieira Soares (Editor Adjunto). Publicado em 15/10/2021.

Copyright @ 2021 RCCC. Todos os direitos reservados. É permitida a citação de parte de artigos sem autorização prévia, desde que identificada a fonte. 
monótonas por videoconferência). Por fim, observa-se uma visão otimista para tendências futuras, com alterações nos aspectos humanos (mudança de paradigma do papel do aluno), institucionais (maior utilização da tecnologia) e formativos (uso de metodologias ativas). Conclui-se que a utilização de metodologias ativas no aspecto didático e pedagógico eleva a participação do número de alunos nas aulas remotas e melhora a qualidade da aprendizagem. $\mathrm{O}$ estudo pode contribuir com as instituições de ensino que adotam o ensino remoto emergencial para continuidade das atividades acadêmicas em períodos de crise, bem como aos docentes que planejam suas atividades, ressaltandose o papel do professor e a importância das metodologias ativas na construção do conhecimento.

Palavras-chave: Covid-19. Ensino remoto. Metodologias ativas. Papel do professor.

\begin{abstract}
This study aimed to investigate the perception of on-site students of the Accounting Sciences Program of a public university that adopted emergency remote learning during the Covid-19 pandemic in Brazil, highlighting the aspects that favor or hinder learning. A qualitative and descriptive study was carried out, with data collected through 4 focus groups with the participation of 80 students from an on-site undergraduate program in Accounting Sciences. The results indicate that the students perceive the structural factors (flexibility in the deadlines for delivery of activities), personal and collective factors (autonomy in the learning process) and didactic-pedagogical factors (use of active methodologies by the professor) as facilitating aspects of the remote education. As for the aspects that hinder learning, we highlight external factors (lack of internet access), individual factors (not maintaining a study routine and increased stress levels) and traditional remote education (monotonous videoconference classes). Finally, an optimistic vision for future trends is observed, with changes in the human aspects (change of paradigm of the student's role), institutional aspects (greater use of technology) and formative aspects (use of active methodologies). It is concluded that the use of active methodologies in the didactic and pedagogical aspect raises the participation of the number of students in remote classes and improves the quality of learning. This study can contribute to educational institutions that adopt emergency remote education for continuity of academic activities in periods of crisis, as well as to professors who plan their activities. It emphasizes the role of the professor and the importance of active methodologies in the development of knowledge.
\end{abstract}

Keywords: Covid-19. Remote education. Active methodologies. Professor's role.

\title{
1 INTRODUÇÃO
}

O uso das tecnologias de informação e comunicação (TIC) ganhou ainda mais espaço no ambiente educacional em decorrência da pandemia de Covid-19 que impactou todo o mundo no ano de 2020 (Sangster, Stoner, \& Flood, 2020). Nos cursos presenciais, seu uso foi implementado para dar continuidade ao desenvolvimento do ensino on-line ou remoto emergencial, suscitando mudanças repentinas (Basilaia \& Kvavadze, 2020; Schmitt, Bugalho, \& Kruger, 2021). Nesse contexto, alunos e professores precisaram se adaptar a essa nova realidade, mediante ajustes comportamentais, no intuito de superar as adversidades frente ao novo cenário repleto de incertezas (Palmeira, Ribeiro \& Silva, 2020).

Nasu (2019) afirma que o uso das TIC no ambiente escolar e acadêmico é uma realidade, tendo em vista a ampla utilização de aparelhos celulares e dispositivos eletrônicos com aplicativos de 
pesquisa, leitura de textos, fala e acesso às redes sociais. A partir disso, são citados diversos benefícios, especialmente no ensino de contabilidade, ressaltando-se os aspectos que elevam os indicadores de frequência e satisfação dos alunos, favorecem a participação e envolvimento nas aulas e auxiliam no processo de ensino e aprendizagem (Ezeani \& Akpotohwo, 2014; Gaviria, Arango, \& Valencia, 2015).

Entretanto, Sangster et al. (2020) destacam diversos desafios que os alunos enfrentam no ensino remoto, sendo eles: problemas relacionados ao acesso à internet; equipamentos inadequados; sobrecarga de leitura; falta de acesso aos recursos de aprendizagem; espaços inadequados para acompanhamento das aulas no ambiente doméstico; professores que preferem atividades tradicionais; dentre outros. Com base em tais desafios, sublinha-se o papel do professor como facilitador no processo de ensino-aprendizagem (Schmitt et al., 2021), sendo oportuna a utilização de metodologias ativas, tendo em vista que os acadêmicos demandam por processos de ensino interativos, dinâmicos e envolventes (Souza, Meurer, Costa, \& Musial, 2020; Palmeira et al., 2020).

No Brasil, com a interrupção das atividades presenciais de ensino devido ao risco de contágio do novo coronavírus, muitas instituições educacionais inicialmente não desenvolveram ações para continuidade das atividades, sendo esta prática observada em algumas universidades privadas e instituições federais de ensino superior (IFES). Nesse ambiente de ensino remoto emergencial, o estudo de Schmitt et al. (2021) investigou as principais estratégias de ensino-aprendizagem, a partir da percepção de uma amostra de docentes dos cursos de Administração, Ciências Contábeis e Ciências Econômicas de quatro instituições de ensino superior no sul do Brasil, durante o período de isolamento social no contexto da pandemia de Covid-19. Os resultados do estudo evidenciam que as principais estratégias de ensino-aprendizagem adotas no formato remoto foram as aulas expositivas com apresentação de slides, resolução de exercícios, estudos de caso e leituras orientadas. Contudo, verifica-se como oportunidade de pesquisa a apresentação de contraponto dessa relação a partir da percepção dos discentes. Assim, surge a questão: Como os alunos do curso presencial de ciências contábeis de uma IFES percebem o ensino remoto emergencial adotado durante a pandemia de Covid19 ?

Para responder à questão, o estudo tem como sujeitos de análise os alunos do curso de graduação em ciências contábeis de uma IFES que adotou o ensino remoto emergencial durante a pandemia de Covid-19 e consiste na investigação da percepção desses acadêmicos acerca das características do processo de ensino-aprendizagem realizado no período indicado para o distanciamento social, ressaltando-se os aspectos que o favorecem ou dificultam a adoção do ensino remoto emergencial. Ao mapear mecanismos que visam minimizar situações indutoras de estresses, Lopes, Meurer e Voese (2018) afirmam que é importante considerar a percepção do estudante, tendo em vista que o desempenho acadêmico e a aprendizagem também são consequências do estado emocional do aluno. Nesse sentido, Gaviria et al. (2015) defendem que a adoção de técnicas de ensino e métodos variados podem auxiliar os discentes de contabilidade a ter melhor desempenho na aprendizagem.

Diante do exposto, justifica-se o estudo pela oportunidade de pesquisa que se apresenta, tendo em vista a adoção do ensino remoto emergencial nos cursos presenciais no período de distanciamento social provocado pela Covid-19, sendo reforçada a relevância da TIC no contexto educacional, bem como o emprego de metodologias ativas para promover o processo de ensino-aprendizagem (Palmeira et al., 2020). Dessa forma, conhecer a percepção dos acadêmicos acerca desse processo poderá contribuir com as instituições de ensino no enfrentamento de situações de crise e dificuldades relacionadas ao ensino remoto emergencial. Ainda, os resultados podem contribuir com o processo de ensino dos docentes de contabilidade, sendo ressaltadas as características apontadas pelos estudantes como facilitadoras, bem como aquelas situações que não favorecem à aprendizagem. Seus achados 
também podem contribuir aos próprios acadêmicos na definição de estratégias para o enfrentamento das adversidades que podem surgir com a adoção do ensino remoto emergencial na formação profissional.

\section{REFERENCIAL TEÓRICO}

\subsection{Processo de ensino-aprendizagem}

É inegável que a educação tem papel transformador na vida dos indivíduos, pois o ensino deve ser pensado como um processo de inter-relação entre quem ensina e aquele que aprende, instrumentalizado por modelos pedagógicos e metodologias aplicadas em sala de aula. Com isso, diferentes teorias do ensino-aprendizagem são identificadas na literatura, destacando-se no ensino de contabilidade a teoria da aprendizagem experiencial (Oliveira, Raffaelli, Colauto, \& Casa Nova, 2013; Ferreira, Leal \& Farias, 2020; Palmeira et al., 2020; Moreira, Alves, Andreassi \& Braga, 2020).

Com base na abordagem cognitiva, Kolb (1984) desenvolveu a teoria da aprendizagem experiencial, considerando que o processo de ensino e assimilação do conhecimento é uma construção social resultante da interação e cooperação entre sujeitos, bem como da ressignificação das experiências anteriores a partir do pensamento crítico em relação às novas informações adquiridas. Assim, a aprendizagem experiencial parte da premissa de que todo o processo de aprendizagem é criado por meio da transformação da experiência vivenciada em conhecimento (Oliveira, et al., 2013).

Nessa perspectiva, Kolb (1984) estruturou a Learning Style Inventory (LSI) para identificar como os indivíduos constroem sua aprendizagem, levando em consideração dois eixos: (i) a percepção, que pode ser baseada na Experiência Concreta ou na Conceptualização Abstrata; e (ii) o processamento, que pode seguir a Experiência Ativa ou a Observação Reflexiva. A partir das diferentes combinações entre os tipos de percepção e processamento, Kolb (1984) propõe a estruturação de estilos de aprendizagem: acomodador (combinação da Experiência Concreta e Experiência Ativa, representado por indivíduos que preferem o uso de atividades intuitivas, tais como trabalhos em grupo); assimilador (combinação da Conceptualização Abstrata e Observação Reflexiva, perfil que prioriza a leitura e interpretação de teorias); convergente (combinação da Conceptualização Abstrata e Experiência Ativa, alunos que preferem a aplicação prática de teorias em exercícios e experimentos); e, divergente (combinação da Experiência Concreta e Observação Reflexiva, estilo de aprendizagem que desenvolve o conhecimento a partir do debate e discussões).

$\mathrm{Na}$ seara do ambiente educacional a distância, sob a lente da aprendizagem experiencial, Palmeira et al. (2020) abordam o emprego de metodologias ativas como recursos didáticos no ensino remoto, centrado no pensamento crítico, reflexivo e analítico dos estudantes. Os autores concluem que o uso de metodologias ativas impacta no modo com que o estudante vivencia a sua aprendizagem, estrutura seu modo de aprender e ressignifica o conhecimento, fomentando sua autonomia e o desenvolvimento do pensamento crítico. Nesse sentido, sublinha-se o apontamento de Souza et al. (2020) ao destacar que a identificação dos estilos de aprendizagem discentes auxilia o professor no planejamento das atividades a serem desenvolvidas, reforçando mais uma vez o papel do professor na construção do conhecimento.

No processo de ensino-aprendizagem dos estudantes de graduação em ciências contábeis, Oliveira et al. (2013), ao analisarem as relações dos estilos de aprendizagem dos estudantes de ciências contábeis e o emprego de estratégias lúdico-pedagógicas, identificam como estilos de aprendizagem preponderantes o acomodador e o divergente, dentre os estudantes de contabilidade participantes da pesquisa, concluindo que há relação positiva do emprego de estratégias lúdicas no estilo de 
aprendizagem dos estudantes. Ainda na área contábil, Ferreira et al. (2020) desenvolveram um estudo com o objetivo de identificar as competências desenvolvidas no estágio docência, na percepção dos alunos de pós-graduação em contabilidade, com base na teoria da aprendizagem experiencial. Os resultados do estudo evidenciam que o conhecimento teórico, associado à vivência prática do ensino, desenvolvem as competências necessárias à docência.

Nesse cenário, apresenta-se como desafio aos professores do ensino superior de contabilidade a construção da sua identidade docente (Lima \& Araujo, 2019), visto que a formação desse profissional o direciona para os aspectos teórico-práticos relacionados ao mercado de trabalho, tornando-o especialista na sua área, sem uma adequada formação pedagógica (Korhonen \& Törmä, 2016). O estudo desenvolvido por Ferreira (2015) chama a atenção para o fato de que os professores de cursos de ciências contábeis identificam-se com o "ser-contador" mais do que com o "serprofessor", ressaltando a atividade docente como uma extensão da prática profissional. No entanto, para desenvolver a docência, o então contador, agora professor, precisa desenvolver novas habilidades, dentre as quais identifica-se na literatura o emprego da TIC e metodologias ativas (Palmeira et al., 2020).

Ademais, Oliveira et al. (2013) argumentam que as alterações no mercado de trabalho pressionam as instituições de ensino superior que oferecem cursos de contabilidade a modificar suas estruturas a fim de atender novos conhecimentos, habilidades e competências exigidas na dinâmica laboral do profissional contábil. Essas exigências ressaltam o papel do professor na formação dos futuros profissionais em relação ao atendimento das demandas da sociedade quanto aos aspectos técnicos, teóricos e éticos.

\subsection{Uso de TIC e metodologias ativas no ensino}

Muitas instituições de ensino e empresas aderiram aos processos educacionais pela internet para proporcionar treinamento aos seus alunos e colaboradores, visto que necessitam permanecer em constante evolução e aprendizagem para continuidade de suas formações e funções profissionais, sendo tal processo conhecido como e-learning (Kraemer, 2004). Com os avanços tecnológicos e as mudanças constantes, o e-learning foi incorporado ao ensino profissional, sendo apontado como um dos mecanismos de apoio ao ensino a distância - EaD (Kraemer, 2004). A partir da adoção interativa da TIC, como a modalidade e-learning, alguns estudiosos defendem a transição do ambiente presencial, tradicionalmente utilizado no processo de aprendizagem e formação acadêmica, para o desenvolvimento do ensino on-line ou remoto, em que os alunos se envolvem nas tarefas a seu tempo e ritmo, comunicando-se com professores e colegas com o auxílio da internet (Abdous, 2019; Basilaia \& Kvavadze, 2020).

$\mathrm{Na}$ perspectiva desenvolvimentista do ensino on-line ou remoto, cada vez mais mutável e interativo, as instituições de ensino que ofertam cursos de ciências contábeis devem estar atentas e acompanhar o processo de evolução na adoção de novas TIC, bem como as tendências da prática contábil (Nasu, 2019). No que tange à tais tendências, Janvrin e Watson (2017) e Abdous (2019) afirmam que habilidades e competências dinâmicas são exigidas atualmente no mercado de trabalho do profissional contábil. No caso particular do ensino remoto emergencial, Palmeira et al. (2020) informam que a adoção da TIC é lenta em muitas instituições de ensino, posição que reforça a importância do presente trabalho, a julgar pelo possível impacto da morosidade no desempenho dos atores vinculados ao processo de aprendizagem remota.

Com o desenvolvimento da TIC e o surgimento de ambientes virtuais de ensino-aprendizagem (AVEA), diferentes formas de ensino são incentivadas para elevar o desempenho acadêmico, seja nos 
cursos presenciais ou a distância, com destaque para metodologias ativas que empregam, dentre outras abordagens, a problematização (Silva, Colle, Cavichioli, \& Souza, 2018) e estratégias lúdicas, tais como jogos e gamificação (Oliveira et al., 2013; Bornal, Barbante Junior, Matsuoka, \& Nasu, 2019; Souza, et al., 2020; Nasu \& Nogueira, 2020; Nemer, Ramirez, Frohmut, \& Bergamo, 2020). Os estudos referenciados apontam como benefícios das estratégias da aprendizagem ativa a maior participação do aluno nas aulas, tendo em vista que ele é provocado a sair da sua zona de conforto, além de despertar seu interesse pela pesquisa e apresentar um feedback do seu desempenho em tempo real.

De acordo com Diesel, Baldez e Martins (2017), os princípios basilares das metodologias ativas são: o aluno no centro do processo de ensino-aprendizagem; autonomia; reflexão; problematização da realidade; trabalho em equipe; inovação; e, o professor como mediador, facilitador e ativador do conhecimento. Gainor, Bline e Zheng (2014) caracterizam a aprendizagem ativa a partir da utilização de técnicas educacionais que envolvem o estudante na construção do conhecimento, enquanto o ensino tradicional visa a transmissão do conteúdo e assimilação de forma passiva. Por outro lado, Bonwell e Eison (1991) elencam elementos que caracterizam as estratégias pedagógicas que permitem a aprendizagem ativa, tais como: envolvimento dos alunos no processo de aprendizagem; ênfase no desenvolvimento de habilidades do aluno; desenvolvimento da capacidade de raciocínio; maior engajamento do aluno nas atividades; e, uso de técnicas que trabalham os valores do aluno. Com isso, observa-se que as metodologias ativas são indicadas tanto no ensino presencial quanto no remoto, tendo o professor como articulador e facilitador no processo ensino-aprendizagem.

Nesse aspecto, a função do professor é destaque na relação entre o uso das estratégias e a adaptação do modelo de ensino. Dessa forma, o uso das TIC contribui com a formação dos acadêmicos no processo de ensino-aprendizagem, tanto no ensino presencial, quanto no remoto. Para tanto, se faz necessário que o professor estruture um formato para condução do processo, não apenas baseado na participação do aluno, mas nas oportunidades alicerçadas em três dimensões (Côrte Vitória, Casartelli, Rigo, \& Costa, 2018): (i) afetiva, que envolve o desejo de aprender; (ii) cognitiva, contemplando a motivação intelectual; e (iii) comportamental, que se refere ao engajamento do estudante para aprender e praticar aquilo que aprende. O planejamento estratégico das atividades acadêmicas e a disponibilização antecipada dos conteúdos pelo professor, com o emprego de plataformas digitais são instrumentos que apoiam o docente no processo de transformar o aluno passivo (papel tradicional) no estudante protagonista e ativo na construção do conhecimento (Nogueira, 2014; Nasu \& Afonso, 2018). Com esse entendimento, Leal, Miranda e Casa Nova (2017) entendem que o uso da TIC combinado com as metodologias ativas pode contribuir para melhorar o ensino de contabilidade.

No contexto do ensino de ciências contábeis, em relação ao planejamento estratégico das atividades acadêmicas, Silva e Bruni (2017) destacam que a aprendizagem ativa ocorre a partir da estruturação de ações que incluem as experiências vivenciadas no ambiente em que o estudante está inserido, sugerindo algumas estratégias: aulas expositivas dialogadas; estudos dirigidos; aprendizagens experienciais com profissionais que atuam no mercado; seminários, mesa redonda e debates; aprendizagem baseada em problemas (PBL); ensino a distância com grupos de discussão online; estudo de casos; oficinas, escritórios, laboratórios ou empresas modelo; simulações e jogos.

No cerne do planejamento acadêmico devem estar presentes as TIC. Gaviria et al. (2015) ressaltam que o uso da tecnologia e emprego de ambientes virtuais no ensino podem auxiliar o estudante no processo da aprendizagem, assim como melhorar o seu desempenho. Leal et al. (2017) entendem que o uso da TIC combinado com as metodologias ativas pode contribuir para melhorar o ensino de contabilidade. Entretanto, docentes e discentes de ciências contábeis podem apropriar-se das TIC de forma não tão eficiente. Nasu (2019) observa que mesmo com as mudanças recentes nas 
práticas do ensino, em geral, provocadas pelo emprego da TIC, muitos alunos de cursos de ciências contábeis ainda não conseguiram acompanhar essa realidade. Watty, McKay e Ngo (2016) identificaram que as principais dificuldades enfrentadas na adoção das TIC nos cursos de ciências contábeis estão relacionadas aos professores, sendo apontado: resistência do corpo docente que prefere métodos tradicionais de ensino; ações individuais de novos professores desencorajadas pelos mais antigos; zona de conforto; incapacidade do corpo docente para uso de TIC e falta de apoio institucional; e, sobrecarga na jornada de trabalho/falta de tempo.

De fato, a literatura aponta que os métodos tradicionais de ensino empregados em cursos presenciais que utilizam abordagens passivas, como a leitura de textos e aulas expositivas, desmotivam o aluno que espera maior estímulo visual e o uso de metodologias ativas, apoiada nos aparelhos eletrônicos e aplicativos de celulares que já fazem parte do seu cotidiano (Nasu, 2019; Souza, et al., 2020; Nasu \& Nogueira, 2020; Nemer, et al., 2020).

\section{METODOLOGIA}

O estudo se classifica como qualitativo e descritivo, cujos dados foram coletados mediante a realização de grupos focais com a participação de alunos do curso de graduação em ciências contábeis, matriculados no primeiro semestre de 2020, em uma IFES que adotou o ensino remoto emergencial no período de distanciamento social, em decorrência da pandemia da Covid-19. Assim, os participantes da pesquisa são alunos do curso presencial de ciências contábeis, cuja carga horária total é de 3.000 horas/aula, distribuídas em 10 semestres, com oferta de disciplinas e turmas no período diurno e noturno, composto por 390 alunos matriculados (207 no curso noturno e 183 no curso diurno).

Com a interrupção das atividades presenciais de ensino, devido ao risco de contágio do novo coronavírus, a IFES estudada, localizada no Estado do Rio Grande do Sul, adotou o Regime de Exercícios Domiciliares Especiais (REDE), caracterizado como uma combinação da excepcionalidade dos exercícios domiciliares com o ensino remoto, apoiado em Tecnologias Educacionais em Rede (TER). Seu desenvolvimento requer a adaptação da modalidade presencial para o ensino remoto, com o uso de recursos diferenciados para realização das aulas, contendo atividades continuadas e formativas, com presencialidade virtual (aulas síncronas) e videoaulas (aulas assíncronas) para acesso a qualquer tempo, com a validação da presença mediante a entrega de atividades. Contudo, o REDE necessita da utilização de AVEA, como o Moodle, e plataformas digitais de videoconferência, como o Google Meet e Zoom.

Com foco no aluno, as primeiras ações implementadas visam acolhimento e garantia da continuidade do ensino. Porém, ao considerar as dificuldades vivenciadas pelo aluno, o REDE foi instituído inicialmente na forma de adesão voluntária, em que o aluno poderia optar pelo modo remoto ou aguardar o retorno presencial. Entretanto, os alunos do curso de ciências contábeis da instituição tiveram grande adesão ao REDE no primeiro semestre de 2020, apresentando-se como desafio aos docentes a transposição dos conteúdos para o ensino remoto, planejados inicialmente como aulas presenciais.

Diante dessas informações foram escolhidas por conveniência duas disciplinas obrigatórias e outras duas optativas, cujo ensino remoto emergencial se deu mediante adoção do REDE, sendo selecionadas aquelas disciplinas da grade curricular que abarcam alunos que já passaram pelas disciplinas introdutórias no ensino presencial. Desse modo, optou-se por uma amostra de alunos matriculados a partir do sexto semestre, sendo apresentados na Tabela 1. 
Tabela 1

Participantes de pesquisa

\begin{tabular}{l|c|c|c|c|c}
\hline \multicolumn{1}{c|}{ Disciplinas } & $\begin{array}{c}\text { Carga } \\
\text { horária }\end{array}$ & $\begin{array}{c}\text { Alunos } \\
\text { matriculados }\end{array}$ & $\begin{array}{c}\text { Alunos no } \\
\text { REDE }\end{array}$ & $\begin{array}{c}\text { Participantes } \\
\text { da pesquisa }\end{array}$ & $\begin{array}{c}\text { Semestre } \\
\text { no curso }\end{array}$ \\
\hline $1^{1}$ & $60 \mathrm{hs}$ & 32 & 26 & 22 & $6^{\mathbf{o}}$ \\
\hline $2^{2}$ & $30 \mathrm{hs}$ & 39 & 37 & 32 & $7^{\mathbf{2}}$ \\
\hline $3^{1}$ & $30 \mathrm{hs}$ & 6 & 6 & 6 & $8^{\mathbf{o}}$ \\
\hline $4^{2}$ & $60 \mathrm{hs}$ & 28 & 21 & 20 & $9^{\mathbf{o}}$ \\
\hline Total & & 105 & 90 & 80 & - \\
\hline
\end{tabular}

Fonte: Dados da pesquisa.

Legenda: ${ }^{1}$ Disciplina ofertada no período diurno; ${ }^{2}$ Disciplina ofertada no período noturno.

As disciplinas apresentadas na Tabela 1 foram enumeradas para garantir o sigilo e não permitir a identificação dos participantes do estudo. Assim, a disciplina 1 é obrigatória na matriz curricular do curso, ofertada aos alunos do $6^{\circ}$ semestre, com carga horária total de 60 horas/aula. Já a disciplina 2, também é uma disciplina obrigatória, ofertada aos alunos do $7^{\circ}$ semestre, com carga horária de 30 horas/aula. Em relação às disciplinas complementares, consideradas optativas, são representadas pela disciplina 3, na matriz curricular do $8^{\circ}$ semestre, com carga horária de 30 horas/aula, e disciplina 4, do $9^{\circ}$ semestre, com carga horária de 60 horas/aula. Essas disciplinas contam com o total de 105 alunos matriculados (26,92\% dos alunos do curso). No entanto, observa-se que $85,71 \%$ dos alunos aderiram ao $\operatorname{REDE}(\mathrm{n}=90)$, demonstrando o alto índice de adesão do curso no ensino remoto emergencial. Por outro lado, os 15 alunos que não aderiram irão recuperar as atividades no calendário suplementar. Ao serem questionados pela coordenação do curso, esses alunos alegaram dificuldade de acesso à internet e outros problemas pessoais.

Como sujeitos da pesquisa, identificam-se 80 alunos que aceitaram participar do estudo, totalizando $88,8 \%$ dos alunos optantes pelo REDE, o que representa $20,51 \%$ do total de alunos matriculados no curso no primeiro semestre de 2020. Selecionados os participantes, a etapa seguinte se dedicou à coleta dos dados com a utilização de 4 grupos focais, seguindo um roteiro semiestruturado de questões, sendo utilizadas 4 reuniões virtuais, por meio do Google Meet, no período de 17 a 31 de julho de 2020, após o término das atividades de ensino desenvolvidas de forma remota nas disciplinas no primeiro semestre 2020. Essas reuniões virtuais foram gravadas com a autorização dos participantes para posterior transcrição, sendo observada duração média de 85 minutos, cada.

Nos grupos focais, os participantes foram informados dos objetivos do estudo, ressaltando-se os aspectos éticos da pesquisa, sigilo e confidencialidade, sendo disponibilizado Termo de Consentimento Livre e Esclarecido (TCLE), que incluiu questões para caracterização do perfil dos participantes. Essas questões visam contextualizar os grupos focais, utilizando estatística descritiva baseada na frequência em escalas, sendo: idade do aluno (até 20 anos, de 21 a 25 anos, de 26 a 30 anos, de 31 a 35 anos, mais de 36 anos), sexo (M - Masculino; F - Feminino); Estado Civil (S Solteiro; C - Casado; O - Outro); Número de Filhos; Número de pessoas na mesma residência; Ocupação (T - Trabalha; TR - Trabalho remoto ou home office; NT - Não trabalha; E - Estágio; B Bolsista); Número de disciplinas cursadas no semestre (até duas; três; quatro; cinco ou mais); Acesso à internet (Apenas no celular; Wi-fi em casa; Wi-fi em outro local; Não possui acesso); e, Condições de renda do grupo familiar (até 1 salário mínimo; de 1 até 3 salários mínimos; de 3 até 5 salários mínimos; acima de 5 salários mínimos).

Por sua vez, os temas que compõem o roteiro de questões abordadas nos grupos focais (Tabela 2) toma por base os estudos anteriores, visando identificar a percepção dos participantes quanto aos 
aspectos que facilitaram ou dificultaram o ensino-aprendizagem no ensino remoto emergencial e as necessidades de adequações, bem como as expectativas futuras.

Tabela 2

\section{Temas abordados nos grupos focais}

\section{Questões}

Como você percebe seu nível de estresses nesse semestre em comparação aos anteriores?

Como foi seu processo de adaptação para essa nova modalidade de ensino remoto no REDE?

Como você avalia esse processo de ensino no REDE?

$\mathrm{Na}$ sua opinião, quais foram os aspectos que contribuíram ou facilitaram para o alcance dos objetivos no REDE?

Na sua opinião, quais foram os aspectos que não contribuíram ou dificultaram o alcance dos objetivos?

Como você avalia seu desempenho acadêmico nesse semestre com o ensino remoto?

Na sua percepção, o que funcionou e o que não funcionou com o ensino remoto?

O que você percebe que precisa mudar ou quais aspectos precisam ser revistos para atingir melhor resultado?

Quais são as tendências para o futuro, pós-pandemia?

Perfil (Idade, sexo, estado civil, número de filhos; número de pessoas na residência, ocupação, quantas disciplinas cursou no semestre, acesso à internet, condições de renda)

Fonte: Elaborado pelos autores.

É importante destacar que os participantes da pesquisa tiveram livre manifestação a cada questão apresentada, sendo estimulados a debater em conjunto nos grupos focais. Salienta-se que foi realizado um grupo focal para cada disciplina, em que os alunos discutiam em conjunto o tema proposto. Após a realização dos grupos focais e transcrição das falas, os dados foram analisados por meio da análise de conteúdo (Bardin, 2011), sendo observadas a posteriori as categorias de análise: situações estressoras; fatores que contribuem à adoção do ensino remoto emergencial (estruturais; pessoais e coletivos; e, didáticos e pedagógicos); fatores que dificultaram o processo (externos; individuais; e, práticas docentes); e, expectativas futuras (humanos; institucionais; e, formativos).

\section{RESULTADOS E DISCUSSÕES}

Para apresentação dos resultados do estudo, inicialmente foi caracterizado o perfil do aluno do curso de graduação em ciências contábeis participante da pesquisa, conforme a Tabela 3, sendo observada a frequência para verificar que, no geral, os participantes da pesquisa se identificam com idade entre 21 e 30 anos $(58,8 \%)$, do sexo feminino (61,2\%), solteiro (60,0\%), cuja ocupação, além da atividade estudantil, trabalha ou encontra-se em atividade domiciliar (home office) (50,0\%), sem filhos $(80,0 \%)$, que reside com 3 pessoas ou mais $(70,0 \%)$, com renda familiar acima de 3 salários mínimos $(73,8 \%)$, com acesso à internet na residência $(65,0 \%)$ e cursando no primeiro semestre de 2020 quatro disciplinas ou mais (78,8\%). Na Tabela 3 não está apresentada a descrição de raça, contudo 8 alunos se identificam como negros (10\%) e 72 como brancos (90\%).

Cabe salientar que o perfil identificado representa a maioria dos participantes da pesquisa, contudo há situações pontuais de alunos que foram muito afetados com a pandemia, tendo a renda familiar reduzida, sem acesso à internet em casa, contanto apenas com o celular para participar das aulas ou precisando se deslocar a outro ambiente (como o local de trabalho) para ter acesso ao conteúdo das disciplinas. Também há relatos de alunos que não conseguiram participar das aulas síncronas por falta de condições ou infraestrutura ideal, pois não havia espaço adequado em sua residência, assim como possuía apenas um computador, compartilhado com os filhos em idade escolar 
ou outro membro familiar que também estavam com aulas on-line. Esse resultado corrobora com o estudo de Sangster et al. (2020) que elenca tais desafios enfrentados pelos alunos na adoção do ensino remoto emergencial.

Tabela 3

Perfil dos participantes da pesquisa

\begin{tabular}{|c|c|c|c|c|c|}
\hline Idade & $\mathrm{N}^{\mathbf{0}}$ alunos & Frequência & Sexo & $\mathbf{N}^{\circ}$ alunos & Frequência \\
\hline Até 20 anos & 08 & $10,0 \%$ & Masculino & 31 & $38,8 \%$ \\
\hline De 21 até 25 anos & 26 & $32,5 \%$ & Feminino & 49 & $61,2 \%$ \\
\hline De 26 até 30 anos & 21 & $26,3 \%$ & Total & 80 & $100,0 \%$ \\
\hline De 31 até 35 anos & 14 & $17,5 \%$ & & & \\
\hline Acima de 36 anos & 11 & $13,7 \%$ & Estado Civil & $\mathrm{N}^{\mathrm{o}}$ alunos & Frequência \\
\hline \multirow[t]{2}{*}{ Total } & 80 & $100,0 \%$ & Solteiro & 48 & $60,0 \%$ \\
\hline & & & Casado & 21 & $26,3 \%$ \\
\hline Ocupação & $\mathrm{N}^{\circ}$ alunos & Frequência & Outros & 11 & $13,7 \%$ \\
\hline Trabalha fora & 18 & $22,5 \%$ & Total & 80 & $100,0 \%$ \\
\hline Trabalho remoto & 22 & $27,5 \%$ & & & \\
\hline Não trabalha & 20 & $25,0 \%$ & $\mathbf{N}^{0}$ de Filhos & $\mathrm{N}^{0}$ alunos & Frequência \\
\hline Estágio & 15 & $18,7 \%$ & 0 & 64 & $80,0 \%$ \\
\hline Bolsista & 05 & $6,3 \%$ & 1 & 11 & $13,7 \%$ \\
\hline \multirow[t]{2}{*}{ Total } & 80 & $100,0 \%$ & 2 ou mais & 05 & $6,3 \%$ \\
\hline & & & Total & 80 & $100,0 \%$ \\
\hline $\mathbf{N}^{0}$ pessoas na casa & $\mathrm{N}^{\circ}$ alunos & Frequência & & & \\
\hline 1 pessoa & 08 & $10,0 \%$ & Internet & $\mathrm{N}^{0}$ alunos & Frequência \\
\hline 2 pessoas & 16 & $20,0 \%$ & Celular & 16 & $20,0 \%$ \\
\hline 3 pessoas & 31 & $38,8 \%$ & Wi-fi casa & 52 & $65,0 \%$ \\
\hline 4 pessoas ou mais & 25 & $31,2 \%$ & Wi-fi outro & 12 & $15,0 \%$ \\
\hline \multirow[t]{2}{*}{ Total } & 80 & $100,0 \%$ & Sem acesso & 0 & - \\
\hline & & & Total & 80 & $100,0 \%$ \\
\hline Condições de renda & $\mathbf{N}^{\mathbf{o}}$ alunos & Frequência & & & \\
\hline Até 1 salário-mínimo & 03 & $3,7 \%$ & Disciplinas & $\mathbf{N}^{\circ}$ alunos & Frequência \\
\hline De 1 a 3 salários & 18 & $22,5 \%$ & Até 2 & 05 & $6,3 \%$ \\
\hline De 3 a 5 salários & 31 & $38,8 \%$ & 3 & 12 & $15,0 \%$ \\
\hline Acima de 5 salários & 28 & $35,0 \%$ & 4 & 42 & $52,5 \%$ \\
\hline Total & 80 & $100,0 \%$ & 5 ou mais & 21 & $26,2 \%$ \\
\hline
\end{tabular}

Fonte: Dados da pesquisa.

As situações relatadas pelos participantes da pesquisa foram ponderadas e motivaram a adoção do REDE como opcional, sendo indicado inicialmente aos docentes o desenvolvimento de ações que visavam o acolhimento do aluno e buscavam alternativas para o enfrentamento dessas dificuldades. Como ações específicas, a instituição de ensino lançou editais para empréstimos de computadores e a oferta de bolsas de auxílio financeiro para o custeio do acesso à internet aos alunos carentes.

Traçado o perfil dos participantes, foi investigado o nível de estresses dos alunos, tendo em vista os eventos estressores desse período. Os participantes da pesquisa relatam situações vivenciadas que evidenciam as angústias que causam estresses, sendo observada a preocupação dos discentes a partir de trechos das suas falas: (i) incertezas quanto ao futuro e a formatura, (ii) novidades na rotina e demora na adaptação ao ensino remoto, (iii) problemas financeiros e pressão no trabalho, (iv) acúmulo nas atividades acadêmicas, e (v) medo da doença e contágio na pandemia de Covid-19. 
Em contraponto, observa-se que alguns alunos não identificaram aumento de estresses, ressaltando-se a resiliência e a inteligência emocional como fatores contributivos para o enfrentamento das dificuldades. No entanto, ao confrontar esse dado com o perfil dos participantes da pesquisa, observa-se que esses mesmos alunos moram com os pais e estão dentre aqueles com maior renda no grupo familiar. Esse dado revela que as condições financeiras e estrutura familiar contribuem para o enfrentamento das situações estressoras, corroborando com os resultados apresentados no estudo de Lopes et al. (2020), em que, o contexto socioeconômico pode contribuir no desenvolvimento de estruturas para o enfrentamento das dificuldades, não afetando o desempenho acadêmico e as habilidades profissionais.

Quanto ao processo de adesão ao REDE, os participantes da pesquisa foram questionados sobre a sua adaptação nessa nova realidade de ensino. As respostas revelam que a maioria dos alunos não estava preparada para essa mudança. Dentre os participantes do estudo, muitos manifestaram a demora para aderir ao REDE, pois acreditavam na volta das atividades presenciais no curto prazo. Contudo, como esse retorno não aconteceu e permaneceram as aulas por meio de videoconferências e disponibilização dos conteúdos via Moodle, esses alunos reconheceram a necessidade de adequações e muitos conseguiram recuperar e desenvolver as atividades propostas.

Nesse sentido, os alunos participantes do estudo mencionam que nem mesmo os professores estavam preparados para o ensino remoto no primeiro momento, pois alguns só desenvolveram atividades após transcorridas algumas aulas. Além disso, os participantes mencionam o ambiente profissional, medo de contágio da doença e dificuldades pessoais para organizar a rotina de estudos, como elementos que aumentaram as incertezas e dificultaram o processo. Tais resultados corroboram os achados de Hedges (2017) que identificou que os alunos do ensino on-line são mais ansiosos que aqueles do ensino tradicional, sobretudo em cursos considerados complexos, como estatística e contabilidade.

Por outro lado, destaca-se que os alunos com experiência anterior no ensino a distância (EaD) apresentam maiores facilidades de adaptação. Esse resultado reforça os achados de Abdous (2019) que também menciona as experiências positivas anteriores com ensino remoto como aspectos que facilitam a aprendizagem, enquanto emoções negativas e o aumento da ansiedade são elementos que impedem o desenvolvimento do aluno no formato do ensino on-line. Contudo, é importante ressaltar que o ensino remoto emergencial adotado no REDE não segue os paradigmas do ensino EaD, cujo funcionamento possui aspectos e legislações próprias.

Ao serem questionados sobre a sua avaliação acerca do REDE, os participantes da pesquisa reconhecem sua importância e destacam como muito positivo o fato de a instituição ter adotado o ensino remoto imediatamente à paralisação das atividades presenciais. Contudo, identifica-se dentre as respostas que, no início do processo, a ausência de definições e a falta de clareza nas comunicações à comunidade acadêmica causaram incertezas quanto à validade das atividades desenvolvidas, sobretudo quanto à questão de adesão.

Por esse motivo, alguns alunos mencionam a solicitação do Diretório Central dos Estudantes (DCE) para suspensão do semestre, o que justificaria a baixa adesão ao REDE no início do processo. Nesse ponto, os respondentes destacam a necessidade de maior transparência na definição das estratégias, tanto para professores, quanto para os alunos. Entretanto, de modo geral, na percepção dos participantes da pesquisa, o REDE é avaliado positivamente, cuja adoção ao ensino remoto emergencial demandou uma mudança de postura do aluno, sendo exigido seu maior envolvimento para manter a qualidade do ensino-aprendizagem.

Nesse ponto, observa-se que os alunos relatam a prática docente de alguns professores: "Foram constituídos grupos em aplicativos de conversa para facilitar o contato entre professor $e$ 
alunos"; "Disponibilização dos conteúdos antecipadamente via Moodle"; "Aulas síncronas realizadas seguindo uma rotina de estudos e horários definidos no calendário presencial"; "Gravação das aulas e disponibilização no Moodle para acesso posterior"; "Controle da presença mediante entrega das atividades solicitadas a cada aula"; "Flexibilização na data de entrega das atividades, geralmente aceitas em até uma semana"; "Avaliações em grupos e via Moodle"; e, "Feedback mais rápido".

A partir disso, foram questionados quais aspectos contribuíram ou facilitaram para o alcance dos objetivos do REDE, na percepção dos participantes da pesquisa. As falas apresentadas na Tabela 4 dizem respeito aos seguintes fatores: estruturais; pessoais e coletivos; e, didáticos e pedagógicos.

Tabela 4

Aspectos que contribuíram ou facilitaram para o alcance dos objetivos do REDE

\begin{tabular}{l|l}
\hline Fatores & Aspectos observados nas entrevistas \\
\hline Estruturais & $\begin{array}{l}\text { Realização de aulas virtuais, seguindo o horário definido no calendário ofertado; } \\
\text { Manter rotina de estudos; } \\
\text { Prazos flexíveis para entrega das atividades. }\end{array}$ \\
\hline Pessoais e coletivos & Maior união entre os colegas de turma; \\
& Maior autonomia no processo de aprendizagem; \\
& Possibilidade de utilizar múltiplas fontes para busca de conteúdo; \\
& Não ter que se deslocar até o campus e melhor aproveitamento do tempo.
\end{tabular}

Fonte: Dados da pesquisa.

Em relação aos fatores estruturais, os participantes da pesquisa mencionam a necessidade de o aluno manter uma rotina de estudos, sendo utilizado o calendário de disciplinas ofertado inicialmente para aulas presenciais que serviu para realizar as reuniões virtuais (aulas síncronas). Tal aspecto pode ser verificado a partir da fala de uma respondente, quando diz: "Assim, sabíamos que naquele horário tinha a aula do professor e sentíamos como se estivéssemos na universidade”. Outro ponto identificado como fator estrutural se refere a flexibilização de prazos para entrega das atividades solicitadas para validação da presença aos alunos, pois assim, segundo outro participante da pesquisa, “com o prazo para entrega mais flexível, foi possível cumprir as tarefas solicitadas".

Quanto aos fatores pessoais e coletivos, os participantes da pesquisa ressaltam a maior proximidade entre os colegas, como observado na fala de um aluno "houve maior união para o cumprimento das atividades, seja com explicações adicionais, trocas de informações e ajuda nos exercícios". Destaca-se também o papel ativo do discente no processo de ensino-aprendizagem, sendo observada maior autonomia na construção do conhecimento, como destacado na fala de outro participante: "se eu não estudar e correr atrás, não vou aprender". Nesse ponto, também foi comentado que cabe ao aluno a pesquisa em outras fontes, leituras complementares e busca de alternativas para entendimento do conteúdo, sendo utilizados artigos, videoaulas e outras referências, como verificado no trecho da fala: "quando eu não entendia o conteúdo, buscava material na internet, assistia vídeos no Youtube até conseguir fazer os exercícios". Outro ponto importante mencionado pelos participantes do estudo que residem em outras cidades ou locais afastados do campus universitário se refere ao fato de que o ensino remoto permitiu o acompanhamento das aulas sem a necessidade de deslocamento, possibilitando melhor utilização do tempo, redução das despesas e 
maior convívio familiar, como abordado na fala: "até chegar na universidade a gente perde muito tempo no trânsito e hoje posso usar esse tempo para estudar em casa e ficar com meu filho".

No tocante aos fatores didáticos e pedagógicos, destaca-se que a utilização de metodologias ativas por parte de alguns professores elevam a participação do número de alunos nas aulas virtuais e melhoram a qualidade da aprendizagem. A utilização do Moodle como ambiente virtual para disponibilização de conteúdos, videoaulas e exercícios também é apontado como aspecto positivo. Nesse quesito, a maioria dos respondentes concorda que o professor desempenha importante papel no processo de aprendizagem, sendo observado que a adoção de múltiplos canais de contato do aluno com o professor facilita o feedback e demonstra acessibilidade ao docente (tais como, grupos no WhatsApp, e-mails e aulas por videoconferência). Como o REDE não exige presencialidade virtual nas aulas síncronas, mas a entrega de atividades para atribuição de presença e acompanhamento da evolução do aluno pelo docente, as atividades deveriam ser desenvolvidas e entregues a cada aula, seja via Moodle ou e-mail, de acordo com a solicitação do professor. Ainda, alguns docentes passaram a gravar suas aulas síncronas e disponibilizar para acesso aos alunos que não puderam participar, fato mencionado pelos acadêmicos como benéfico e um avanço em relação às aulas presenciais.

Conforme os participantes da pesquisa, os docentes que adaptaram seus planos de ensino e conteúdos para o ensino remoto, associado à adoção de metodologias ativas e diferentes canais de comunicação, obtiveram maior participação dos alunos nas aulas síncronas e foram nessas disciplinas que os acadêmicos alcançaram melhores desempenhos. Esses resultados reforçam os achados de Cheong, Bruno e Cheong (2012) e Nasu (2019) que destacam o uso de metodologias ativas que estimulam e desafiam o acadêmico, bem como as estratégias de ensino experiencial que desenvolvam habilidade tecnológicas e aproveitam os recursos já utilizados no dia a dia do aluno, como o aparelho celular, por exemplo.

Por outro lado, ao serem questionados quanto aos aspectos que dificultaram ou não contribuíram para o ensino remoto, via REDE, complementado pela questão que visa identificar o que precisa ser melhorado, os participantes da pesquisa destacam os seguintes fatores: externos; individuais; e, práticas docentes, conforme apresentado na Tabela 5.

Tabela 5

\section{Aspectos que não contribuíram ou dificultaram o alcance dos objetivos do REDE}

\begin{tabular}{l|l}
\hline Fatores & Aspectos observados nas entrevistas \\
\hline Externos & Insegurança; \\
& Falta de acesso à internet; \\
& Atividades profissionais; \\
& Falta de um ambiente propício para o estudo em casa. \\
\hline Individuais & Procrastinação e necessidade de melhor gerenciamento do tempo; \\
& Não manter o foco nos estudos / Rotina de estudos; \\
& Cursar muitas disciplinas e cumprir prazos curtos; \\
& Acumulação de atividades para entrega; \\
& Estresses, questões emocionais e pressões pessoais. \\
\hline Práticas docentes & Excesso de atividades/ Prazos curtos para entrega; \\
& Atraso no retorno de e-mails/ Ausência de respostas; \\
& Falta de adaptação de conteúdos para o ensino remoto; \\
& Aulas por videoconferência monótonas, sem motivação ou atrativos; \\
& Despreparo de alguns professores para o uso das tecnologias.
\end{tabular}

Fonte: Dados da pesquisa. 
Observa-se que os alunos identificam como fatores que dificultam o alcance dos objetivos do REDE os aspectos externos, referenciando: insegurança no contexto da pandemia; problemas de acesso à internet; continuidade e maior envolvimento nas atividades profissionais; e, inexistência de um ambiente propício para aprendizagem. Nesse ponto, são recorrentes as manifestações de participantes que mencionam maior pressão no trabalho e medo de perder o emprego. Esse fator pode ser observado na fala de um participante: "Meu trabalho não pode ser realizado de casa... tenho que ir todo o dia e agora parece que aumentou ainda mais e meu chefe vive dizendo que tem muita gente por aí querendo a minha vaga".

Da mesma forma, muitos alunos participantes da pesquisa alegam ter dificuldade de realizar as atividades acadêmicas no ambiente residencial, pois há interferência da família, como destacado na fala de um participante: "Como estou em casa, meu pai acha que não tenho aula. Esses dias estava apresentando um trabalho e ele veio me chamar para ajudar a lavar o carro". Nesse sentido, os respondentes ressaltam que para melhor desempenho, o aluno precisa ter melhor acesso à internet, estabelecer um espaço físico propício à aprendizagem e mudar sua postura perante às adversidades. Em relação aos fatores individuais, os participantes da pesquisa reconhecem a responsabilidade pessoal do aluno, tendo em vista que se faz necessário maior engajamento para o alcance dos objetivos. Assim, são comuns relatos de alunos que procrastinaram nesse período e acabaram tendo acúmulo de atividades nas disciplinas cursadas, percebendo a necessidade de manter uma rotina de estudos. Os participantes da pesquisa que estavam cursando o maior número de disciplinas enfrentaram maiores dificuldades, pois além das aulas virtuais, deviam realizar a leitura dos materiais disponibilizados pelos professores, buscar outras fontes e ainda desenvolver as atividades solicitadas para entrega.

A partir disso, muitos participantes relatam o aumento de estresses, baixa autoestima, incapacidade de resiliência e outras questões emocionais. Tais observações são retratadas no trecho da fala: "Tinha dias que chegava cansada... com exercícios pra fazer, mas até lavar a louça era mais urgente. Ficava nervosa quando não conseguia fazer e, muitas vezes, com vergonha de perguntar". Contrastando com este resultado, no entanto, a maioria dos participantes da pesquisa afirma estar satisfeita com o seu desempenho e menciona ter atingido seus objetivos pessoais nesse período.

Outro fator mencionado como não contributivo ao ensino remoto diz respeito às práticas tradicionais do professor na condução do processo de ensino-aprendizagem. Assim, o excesso de atividades e definição de prazos curtos ou falta de flexibilização para entrega das tarefas não contribuem com o aluno. Nesse ponto, é ressaltada a necessidade de o professor buscar alternativas para manter o engajamento e a participação do discente, bem como demonstrar maior empatia para auxiliá-lo no cumprimento das tarefas, sendo o retorno às demandas dos alunos um ponto importante.

Assim, destacam-se nas falas dos respondentes a necessidade de feedbacks mais rápidos e maior treinamento ao professor para o uso de TIC (como Moodle), bem como o uso de metodologias ativas para diversificação de abordagens, o que torna as aulas virtuais mais interativas, além de demonstrar maior disponibilidade do professor. O papel do professor pode ser verificado na fala: "Tem professor que coloca os slides no Moodle na hora da aula, passa 2 horas lendo aquilo tudo e no final pede um artigo pra entregar na outra semana... Não tem como!". Esses resultados ressaltam os achados de Watty et al. (2016), quanto à resistência de alguns professores que preferem métodos de ensino mais tradicionais, não estando dispostos e preparados para o uso das TIC, sendo resistentes à mudança.

Por fim, os participantes da pesquisa foram indagados quanto às expectativas futuras para o período pós-pandemia, com relação aos processos de ensino-aprendizagem. Nesse sentido, são observados fatores humanos, institucionais e formativos, conforme apresentado na Tabela 6. As 
respostas apresentadas pelos participantes da pesquisa demonstram otimismo e melhorias possíveis no futuro. Os fatores humanos ressaltam os aspectos colaborativos dos indivíduos e da necessidade de olhar para o outro e para o coletivo. São mencionados alguns aspectos que podem ser considerados positivos nesse momento, como o uso das tecnologias para comunicação que aproximam as pessoas, independentemente da distância física. Do mesmo modo, ressalta-se a mudança de paradigma do aluno tradicional no ensino presencial para um sujeito ativo e participativo, sendo este o protagonista na construção do conhecimento.

Dentre os aspectos institucionais, os participantes da pesquisa esperam que seja estabelecido melhor canal de comunicação da instituição com alunos e professores, cujas ações sejam revestidas de maior transparência e visem melhorar o ambiente acadêmico. Dessa forma, os respondentes almejam a disponibilização de cursos e treinamentos nas plataformas digitais em uso no REDE, tanto para professores quanto para alunos, como canais que facilitam a comunicação.

Tabela 6

\section{Expectativas futuras}

\begin{tabular}{l|l}
\hline Fatores & Aspectos observados nas entrevistas \\
\hline Humanos & $\begin{array}{l}\text { Ser humano mais colaborativo; } \\
\text { Mudança de paradigma do aluno; } \\
\text { Maior proximidade entre as pessoas, mesmo à distância. }\end{array}$ \\
\hline Institucionais & $\begin{array}{l}\text { Melhor comunicação da instituição com os alunos e professores; } \\
\text { Possibilidade de implantação de cursos e treinamentos virtuais para professores e alunos; } \\
\text { Maior utilização da tecnologia para o ensino-aprendizagem. }\end{array}$ \\
\hline Formativos & $\begin{array}{l}\text { Adoção de metodologias ativas no ensino; } \\
\text { Possibilidade de um ensino híbrido, com utilização de aulas virtuais e videoaulas; } \\
\text { Adoção de atividades objetivas, voltadas à prática profissional; } \\
\\
\text { Maior estímulo à pesquisa. }\end{array}$ \\
\hline
\end{tabular}

Fonte: Dados da pesquisa.

Nesse ponto, observa-se certa convergência com os fatores formativos, tendo em vista que a expectativa dos alunos para o período pós-pandemia se desenvolva com maior utilização de TIC e adoção de novas metodologias de ensino que integrem atividades práticas e objetivas relacionadas ao cotidiano e experiências do ambiente profissional e à pesquisa, bem como a possibilidade de adoção de um ensino híbrido, tendo horas presencias e horas virtuais. A certeza da mudança pode ser verificada na fala de um dos participantes: "tudo isso aconteceu e a gente percebeu que muita coisa pode ser diferente... certo mesmo é que nada mais será como antes". Contudo, a maioria dos participantes da pesquisa declara sua preferência pelo ensino presencial, como observado na fala: "nada melhor do que o olho no olho e a presença no ambiente acadêmico para a gente aprender".

A partir da percepção identificada, de modo geral, observa-se a relevância do papel do professor na condução do processo de ensino-aprendizagem, sendo a sua abordagem e estratégias pedagógicas fatores determinantes para o desempenho do estudante. Assim, verifica-se que a adoção de TIC e metodologias ativas no ensino, complementadas pelo uso de atividades que priorizam as vivências práticas experienciais do aluno são apontadas como aspectos que facilitam o ensino remoto emergencial.

\section{CONSIDERAÇÕES FINAIS}

Com o objetivo de investigar a percepção dos acadêmicos do curso de ciências contábeis acerca do ensino remoto emergencial adotado em uma IFES no período da pandemia da Covid-19 no 
Brasil, desenvolveu-se o presente estudo, utilizando grupos focais para coleta de dados. Para alcançar o objetivo, o estudo contou com a participação de alunos matriculados em quatro disciplinas do curso de ciências contábeis da instituição que adotou o ensino remoto por meio do REDE. Os resultados apresentados identificam possíveis construtos, na percepção dos participantes do estudo, que podem contribuir ou dificultar a adoção do ensino remoto.

Inicialmente, os participantes da pesquisa reconhecem o aumento do nível de estresses vivenciado no período, tendo como eventos estressores diferentes situações, tais como a pandemia da Covid-19, novidades na rotina, problemas financeiros, pressão relacionada ao ambiente de trabalho, acúmulo nas atividades acadêmicas, incertezas quanto à formatura e o ensino remoto. Como elementos que auxiliam o aluno no enfrentamento de tais situações, ressalta-se a necessidade de melhor estrutura financeira e familiar, resiliência e inteligência emocional.

No tocante à avaliação dos aspectos que contribuem para adoção do ensino remoto emergencial, os participantes da pesquisa reconhecem os fatores estruturais, pessoais e coletivos, e didáticos e pedagógicos. Destaca-se o papel da instituição de ensino como estrutura articuladora para formação do acadêmico, sendo este o centro da atenção. No entanto, emerge nesse contexto a figura do professor como elo entre esses dois pontos (aluno e instituição), cuja abordagem pedagógica e postura didática podem auxiliar no alcance dos objetivos, sendo observada a relevância de uso das TIC e metodologias ativas para o processo de ensino-aprendizagem.

Por outro lado, observa-se que os participantes da pesquisa apontam como aspectos que não facilitam a adoção do ensino remoto os fatores externos, individuais e práticas docentes. Os aspectos "externos" são identificados como eventos estressores e que podem afetar o desempenho acadêmico, considerando a realidade vivenciada por cada indivíduo e a sua forma de enfrentar tais situações. Já os "aspectos individuais" dizem respeito à mudança na postura do aluno que precisa ser um sujeito ativo na construção do conhecimento, enquanto o fator "práticas docentes" se refere ao papel do professor como condutor e orientador nessa construção, pois ainda existem docentes com práticas e posturas que não acompanham o novo perfil exigido pelo aluno, bem como adequadas ao ambiente do ensino remoto.

De modo geral, os resultados apresentados acerca da percepção dos participantes da pesquisa no contexto pandêmico reforçam os achados de estudos anteriores relativos ao papel do professor na condução do ensino e uso de metodologias ativas na construção do conhecimento, principalmente no ensino remoto emergencial. Aqui, ressalta-se a importância do papel dos professores, que precisam se adaptar às novas TIC para oportunizar aos estudantes o aprendizado e o desenvolvimento das habilidades e competências requeridas para a formação profissional.

Diante desse cenário, observa-se que na percepção dos alunos há otimismo quanto às possíveis tendências de mudanças para o período pós-pandemia, sendo observado o estímulo ao uso da TIC como ferramenta educacional, a participação em eventos e aulas remotamente, a adoção do ensino em formato híbrido, com aulas presenciais e virtuais, além do maior uso de metodologias ativas por parte dos professores como auxílio no processo de ensino-aprendizagem e na motivação para manter o aluno focado nos estudos. No entanto, como primeiro contato com o ensino remoto, a maioria dos participantes da pesquisa reconhece a iniciativa da instituição de manter as atividades acadêmicas nesse período da necessidade de distanciamento social, porém, deseja o retorno das atividades presenciais, mas com a possibilidade de oferta de disciplinas em formato híbrido, ou seja, com aulas presenciais e on-line.

Os resultados da pesquisa dizem respeito à percepção de uma amostra de alunos do curso de ciências contábeis de uma instituição federal de ensino superior que aderiu ao ensino remoto emergencial no período da pandemia de Covid-19. Contudo, os constructos identificados podem servir 
de base para estudos futuros, sendo sugerida a realização de pesquisas complementares, cabendo a comparação dos resultados entre diferentes instituições, sejam elas públicas ou privadas, além de um estudo quantitativo com maior participação de alunos de contabilidade para testar os fatores identificados, bem como avaliar o desempenho acadêmico dos alunos no ensino remoto emergencial.

\section{REFERÊNCIAS}

Abdous, M. H. (2019). Influence of satisfaction and preparedness on online students' feelings of anxiety. The Internet and Higher Education, 41, 34-44.

Bardin, L. (2011). Análise de conteúdo. São Paulo: Edições 70.

Basilaia, G., \& Kvavadze, D. (2020). Transition to online education in schools during a SARS-CoV2 coronavirus (COVID-19) pandemic in Georgia. Pedagogical Research, 5(4), 1-9.

Bonwell, C. C., \& Eison, J. A. (1991). Active Learning: Creating Excitement in the Classroom. 1991 ASHE-ERIC Higher Education Reports. ERIC Clearinghouse on Higher Education, The George Washington University, One Dupont Circle, Suite 630, Washington, DC 20036-1183.

Bornal, E. M., Barbante Junior, E. A., Matsuoka, I. N., Nasu, V. H., \& Nogueira, D. R. (2019). Contábil Quiz: Satisfação dos Estudantes de Ciências Contábeis Com o Uso de App no Processo de Ensino-Aprendizagem. Pensar Contábil, 21(74).

Cheong, C., Bruno, V., \& Cheong, F. (2012). Designing a mobile-app-based collaborative learning system. Journal of Information Technology Education: Innovations in Practice, 11(1), 97-119.

Côrte Vitória, M. I., Casartelli, A., Rigo, R. M., \& Costa, P. T. (2018). Engajamento acadêmico: desafios para a permanência do estudante na Educação Superior. Educação, 41(2), 262-269. https://doi.org/10.15448/1981-2582.2018.2.27960

Diesel, A., Baldez, A. L. S., \& Martins, S. N. (2017). Os princípios das metodologias ativas de ensino: uma abordagem teórica. Revista Thema, 14(1), 268-288.

Ezeani, N. S., \& Akpotohwo, F. C. (2014). Integrating information and communication technology (ICT) in accounting education instruction in Ekiti State Universities. International Journal of business and social science, 5(6), 195-204.

Ferreira, M.M. (2015). Docência no ensino superior: aprendendo a ser professor de contabilidade. Tese de Doutorado, Universidade Federal de São Carlos.

Ferreira, L. V., Leal, E. A., \& Farias, R. S. (2020). O papel do estágio docência no desenvolvimento de competências didático-pedagógicas no contexto da pós-graduação em Contabilidade. Revista de Educação e Pesquisa em Contabilidade (REPeC), 14(2). 
Gaviria, D., Arango, J., \& Valencia, A. (2015). Reflections about the use of information and communication technologies in accounting education. Procedia-Social and Behavioral Sciences, 176, 992-997.

Gainor, M., Bline, D., \& Zheng, X. (2014). Teaching internal control through active learning. Journal of Accounting Education, 32(2), 200-221.

Hedges, S. (2017). Statistics Student Performance and Anxiety: Comparisons in Course Delivery and Student Characteristics. Statistics Education Research Journal, 16(1).

Janvrin, D. J., \& Watson, M. W. (2017). “Big Data”: A new twist to accounting. Journal of Accounting Education, 38, 3-8.

Kolb, D. A. (1984). Experiential learning: experience as the source of learning and development. Englewood Cliffs, NJ: Prentice Hall.

Korhonen, V., \& Törmä, S. (2016). Engagement with a teaching career-how a group of Finnish university teachers experience teacher identity and professional growth. Journal of Further and Higher Education, 40(1), 65-82.

Kraemer, M. E. P. (2004). E-Learning na Contabilidade. Revista Catarinense da Ciência Contábil, 3(7), 09-20.

Leal, E. A., Miranda, G. J., \& Casa Nova, S. D. C. (2017). Revolucionando a sala de aula: como envolver o estudante aplicando as técnicas de metodologias ativas de aprendizagem. São Paulo: Atlas.

Lima, J. P. R., \& Araujo, A. M. P. (2019). Tornando-se Professor: Análise do Processo de Construção da Identidade Docente dos Professores de Contabilidade. Advances in Scientific \& Applied Accounting, 12(2).

Lopes, I. F., Meurer, A. M., \& Voese, S. B. (2018). Efeito das Crenças de Autoeficácia no Comportamento Cidadão e Contraproducente dos Acadêmicos de Contabilidade. Advances in Scientific \& Applied Accounting, 11(3).

Lopes, I. F., Meurer, A. M., \& Colauto, R. D. (2020). Estratégias de Coping de Discentes Brasileiros de Ciências Contábeis. Revista de Educação e Pesquisa em Contabilidade (REPeC), 14(2).

Moreira, M. A., Alves, N. J. F., Andreassi, T., \& Braga, J. G. R. (2020). Educação Empreendedora em Contabilidade: da Teoria à Aprendizagem Experiencial. Revista Catarinense da Ciência Contábil, 19, 4.

Nasu, V. H. (2019). Relationship between the Use of Information and Communication Technology (ICT) and Academic Aspects: Perceptions from Brazilian Accounting Students. BASE-Revista de Administração e Contabilidade da Unisinos, 16(2), 235-255. 
Nasu, V. H., \& Afonso, L. E. (2018). Professor, Posso Usar o Celular? Um Estudo sobre a Utilização do Sistema de Resposta do Estudante (SRE) no Processo Educativo de Alunos de Ciências Contábeis. Revista de Educação e Pesquisa em Contabilidade (REPeC), 12(2).

Nasu, V. H., \& Nogueira, D. R. (2020). Celulares a postos? Estudo sobre a percepção de alunos de ciências contábeis acerca do sistema de resposta de audiência (SRA). Enfoque: Reflexão Contábil, 39(1), 01-19.

Nemer, E. G., Ramirez, R. A., Frohmut, B. D. F., \& Bergamo, R. O. C. (2020). Um estudo de caso sobre o uso de gamificação e da realidade virtual na Educação Profissional. Refas-Revista Fatec Zona Sul, 6(5), 1-13.

Nogueira, D. R. (2014). Vento da mudança: estudo de caso sobre a adoção de ambientes virtuais no ensino presencial em Contabilidade. (Doctoral dissertation), Universidade de São Paulo.

Oliveira, A. J., Raffaelli, S. C. D., Colauto, R. D., \& Casa Nova, S. P. D. C. (2013). Estilos de aprendizagem e estratégias ludopedagógicas: percepções no ensino da contabilidade. Advances in Scientific and Applied Accounting, 6(2), 236-262.

Palmeira, R. L., Silva, A. A. R., \& Ribeiro, W. L. (2020). As metodologias ativas de ensino e aprendizagem em tempos de pandemia: a utilização dos recursos tecnológicos na Educação Superior. HOLOS, 5, 1-13.

Sangster, A., Stoner, G., \& Flood, B. (2020). Insights into accounting education in a COVID-19 world. Accounting Education, 29(5), 431-562.

Schmitt, D. C., Bugalho, D. K., \& Kruger, S. D. (2021). Percepções docentes e às estratégias de ensino-aprendizagem durante o isolamento social motivado pelo COVID-19. Revista Catarinense da Ciência Contábil, 20, e3133.

Silva, S. C., Colle, F. E. S., Cavichioli, D., \& de Souza, R. F. (2018). Aprendizado e desenvolvimento de habilidades no curso de Contabilidade: uma pesquisa-ação com o método Team-Based Learning (TBL). Enfoque: Reflexão Contábil, 37(3), 1-19.

Silva, U. B., \& Bruni, A. L. (2017). O que me ensina a ensinar? Um estudo sobre fatores explicativos das práticas pedagógicas no ensino de contabilidade. Revista de Educação e Pesquisa em Contabilidade (REPeC), 11(2).

Souza, A. N. M., Meurer, A. M., Costa, F., \& Musial, N. T. K. (2020). Utilização de metodologias ativas e elementos de gamificação no processo de ensino-aprendizagem da contabilidade: experiência com alunos da graduação. Desafio Online, 8(3).

Watty, K., McKay, J., \& Ngo, L. (2016). Innovators or inhibitors? Accounting faculty resistance to new educational technologies in higher education. Journal of Accounting Education, 36, 1-15. 